\title{
O CONTEÚDO DA FORMAÇÃO ESCOLAR E A CULTURA DA EJA:
}

\section{desafios da ação docente}

\author{
Rosely de Oliveira Macário' \\ Luiz Antônio Gomes Senna²
}

\section{RESUMO}

Este artigo apresenta um estudo que compõe parte de pesquisa enveredada no campo da Educação de Jovens e Adultos (EJA), como fruto de tese de doutorado, que objetiva refletir sobre as vozes que transitam no campo da Educação de Jovens e Adultos (EJA), vinculada à parte relacionada ao Ensino Fundamental das séries iniciais ( $1^{\circ}$ ao $5^{\circ}$ ano). Tal investigação se justifica pela necessidade de analisar alguns estudos já realizados por pesquisadores nesta etapa educativa com vistas a refletir sobre as práticas educativas que se configuram nessa etapa de ensino. Pautados em uma pesquisa do tipo teórico-bibliográfica e documental. Os resultados deste estudo sinalizam a necessidade da aproximação entre o conteúdo da formação docente aos alunos presentes na sala de aula, que, embora configurados em situação de diversidade, encontram-se unidos no desejo unânime de aprender as capacidades linguísticas da leitura/escrita na escola, frente aos desafios posto na sociedade contemporânea.

Palavras-chave: Diversidade. Ensino. Leitura. EJA.

\section{THE CONTENT OF SCHOOL EDUCATION AND THE EJA CULTURE: challenges for the teaching practice}

\begin{abstract}
This article presents a study that is part of a research undertaken in the field of Youth and Adult Education (EJA), as the result of a doctoral thesis, which aims to reflect on the voices in the field of Youth and Adult Education (EJA), linked to the part related to Elementary Education in the initial grades (1st to 5th year). Such investigation is justified by the need to analyze some studies already carried out by researchers in this educational stage with a view to reflect such data based on the questions regarding the educational practices that are configured in this teaching stage. Based on a theoretical-bibliographic and documentary research. The results of this

1 Doutora em Educação. Professora do Departamento de Educação da Universidade Estadual da Paraíba, Campina Grande/PB. Membro do Grupo de Pesquisa Linguagem Cognição Humana e Processos Educacionais. Orcid iD: https://orcid.org/0000-0002-38105241. E-mail: roselymacario@gmail.com

2 Doutor em Linguística Aplicada. Professor Titular do Programa de Pós-Graduação em Educação/Universidade do Estado do Rio de Janeiro. Pesquisador bolsista dos programas PROCIENCIA (UERJ) e Cientistas do Nosso Estado (FAPERJ) e do Centro de Ciências do Estado do Rio de Janeiro. Orcid iD: http: orcid.org./000-0002-1086-8829. E-mail: senna@senna.pro.br
\end{abstract}


study point out to the need for approximation between the content of teacher education and the students present in the classroom, who, although configured in a situation of diversity, are united in the unanimous desire to learn the linguistic skills of reading / writing at school in the face of the challenges posed by contemporary society.

Keywords: Diversity. Teaching. Reading. EJA.

\section{EL CONTENIDO DE LA FORMACIÓN ESCOLAR Y LA CULTURA EJA: desafíos y dilemas ¿Indicar dónde se realizó el estudio? Brasil?}

\section{RESUMEN}

El objetivo de este artículo es analizar y reflexionar sobre las voces que transitan en el campo de la Educación de Jóvenes y Adultos (EJA)en el nivel y ámbito escolar de la escuela primaria, en los grados iniciales $1^{\circ}$ a $5^{\circ}$ año (indicar dónde se realizó la investigación). Esta investigación es importante porque expone la necesidad de destacar estudios sobre las prácticas educativas configuradas en esta etapa de enseñanza. Se utiliza la investigación teórico-bibliográfica y documental y se deduce la la necesidad de una aproximación entre el contenido de la formación del profesorado a los alumnos presentes en el aula, quienes, aunque configurados en una situación de diversidad, están unidos en el deseo unánime de aprender las habilidades lingüísticas de lectura/escritura en la escuela frente a los desafíos que plantea la sociedad contemporánea.

Palabras clave: Diversidad. Docencia. Lectura. EJA.

\section{INTRODUÇÃO}

Este estudo versa sobre alguns apontamentos discursivos reflexivos de cunho teórico, correlacionados à educação básica no âmbito da Educação de Jovens e Adultos (EJA), tendo por objeto questões aplicadas ao ensino orientado para o diálogo entre os sujeitos oriundos de segmentos sociais historicamente excluídos, que acorrem à escola em condição de diversidade.

Neste trabalho problematiza-se a situação concreta de sala de aula dos anos iniciais da EJA, considerando os estudantes reais, não idealizados na figura de aluno tradicionalmente presente na cultura escolar. Neste contexto, focalizam-se os saberes docentes necessários para, por meio do processo de mediação, possibilitar ao aluno avançar no aprendizado da língua materna. 
No entanto, o que significa, nesse caso, dialogar com os sujeitos sociais no aspecto da diversidade na sala de aula? Por onde começar esse diálogo? Que conhecimento acadêmico-científico se torna necessário para a formação acadêmica com atuação docente voltada para uma demanda constituída de pessoas jovens, adultas e idosas na escola pública ou privada? Essa complexidade em lidar com os diferentes sujeitos sociais na instituição pública é observada a partir do momento em que os indivíduos pobres, oriundos das classes populares do Brasil, passam a ter acesso à educação formal, por meio da legislação que universalizou o ensino básico no Brasil e o tornou obrigatório. Nessa conjuntura, constata-se uma longa trajetória em torno de políticas públicas e programas que, nas esferas nacional e regional, tentam erradicar a exclusão escolar e garantir o direito universal de acesso às instituições próprias de ensino e à cultura letrada.

Nessa direção, a pesquisa ora relatada, desenvolvida no âmbito do curso de doutoramento, vislumbrou dialogar com os alunos, especificamente os da modalidade educativa já exposta, no que diz respeito às questões que emergem no ensino da Língua Materna, mais especificamente no ensino de leitura/escrita.

Particularmente, ao se discutir o desafio posto à escola na contemporaneidade, quanto à inclusão social do sujeito da EJA sem necessariamente excluí-lo do sistema educacional, é preciso, também, atentar para a qualidade da formação do seu professor, sobretudo na educação primária, à luz de um tipo de educação que dialogue com o jovem, adulto e o idoso em situação de diversidade etária, geracional e cultural, de grupos sociais entre os 15 e 70 anos. Implica isso ensejar uma formação docente aberta às práticas educativas e a valorizar os saberes dos indivíduos em diferentes contextos culturais.

Em contextos escolares marcados pela pluralidade, torna-se comum a presença de alunos com o seguinte perfil: existem os que não escrevem, mas leem; os que escrevem, mas não leem; e ainda os que nem escrevem e nem leem. Todos inscritos e reunidos numa mesma turma dos anos iniciais do Ensino Fundamental, nas séries iniciais ( $1^{\circ}$ ao $5^{\circ}$ ano). Esse cenário incide 
diretamente na organização das aulas por parte do docente, no sentido de que algum dos grupos, citados anteriormente, poderá ficar ausente das atividades pensadas para o ensino de leitura.

A efetivação deste estudo se deu mediante a realização de uma pesquisa bibliográfica, teórica e documental. Para a obtenção de dados, percorreu-se uma variedade de livros, teses, dissertações, periódicos especializados, anais de encontros científicos e as pesquisas no Banco de Tese da Coordenação de Aperfeiçoamento de Pessoal de Nível Superior (CAPES), a fim de observar os avanços e os dilemas na área da EJA. Tal busca teve como foco as contribuições de estudos voltados para as questões aplicadas ao contexto escolar dessa modalidade de ensino.

Além de indagações sobre o que é recorrente nas produções acadêmicas e quais as lacunas existentes, que ainda persistem nas questões aplicadas ao contexto do presente estudo. Também foi necessário recorrer, paralelamente, aos dados obtidos em pesquisas anteriores, (MACÁRIO, 2014), (MACÁRIO; RODRIGUES, 2018), (MACÁRIO; SENNA, 2018), resultantes da ação docente da pesquisadora, englobando distintas turmas da modalidade de ensino mencionada, em uma instituição pública pertencente à Rede Municipal de Campina Grande, no estado da Paraíba. Tais pesquisas empíricas sustentam dados aqui apresentados relativamente ao perfil do aluno da EJA e suas histórias de vida escolar.

Em termos de estruturação, o presente texto encontra-se organizado em três seções. Na primeira, destacam-se considerações reflexivas em torno do tema, correlacionadas ao marco normativo no campo de atuação da Educação de Jovens e Adultos. Nessa parte, discorre-se sobre os discursos que ecoam na cultura escolar com relação ao que nos impulsiona a pensar a inclusão do aluno, a partir de dois aspectos antagônicos: de um lado, em termos do direito ao acesso à sala de aula, como fruto de uma legislação normativa que regulamenta a oferta de turmas da EJA; de outro lado, sua fraca capacidade de assegurar as condições favoráveis para o sujeito social real, inserido nessas turmas, a assegurar a sua permanência na educação básica nas redes de ensino, sejam estas pública ou privada. 
Na segunda parte, discute-se, dessa vez, o pensamento disseminado em pesquisas que versam sobre a questão relacionada a incluir ou excluir o discente, da EJA, em contexto de diversidade, bem como sobre o lugar do aluno como um sujeito aprendente.

Na fundamentação teórica, busca-se, por meio das contribuições de pesquisadores como Dayrell (2007; 2013), Charlot (2013), Sacristán (2001), Paiva (2006), Nóvoa (2009), Soares (2002), Carrano (2008), Romão (2014) e Senna (2007), entre outros, pensar os processos educacionais de educação inclusiva, dos saberes docentes, que visaram à adequação de práticas pedagógicas a serem apropriadas para as demandas escolares com um histórico de exclusão social, como é o caso das pessoas inseridas nesse contexto.

Além disso, ainda na segunda parte, apresenta-se, através da análise documental na área dos discursos que emergem dos documentos oficiais, a legislação específica da EJA, contrapondo-se com a realidade vivenciada no interior das práticas escolares nessa etapa de ensino.

Na terceira e última parte, expõem-se as considerações finais, os achados significativos da pesquisa, como instrumento de reflexões, destinado ao campo da formação de professores na educação básica, com atuação na EJA.

\section{O MARCO NORMATIVO NO CAMPO DE ATUAÇÃO DA EJA: O DITO E O REALIZADO NA EDUCAÇÃO BÁSICA DE JOVENS, ADULTOS E IDOSOS}

Nesta seção, colocam-se em pauta publicações que norteiam a legislação em vigor no país, no campo da educação escolar, tais como: Lei 9.394/96 - Lei de Diretrizes e Bases da Educação Nacional (LDB); Proposta Curricular do MEC/Ação Educativa - $1^{\circ}$ Segmento do Ensino Fundamental EJA - (1997); Diretrizes Curriculares Nacionais (2000); e Diretrizes Curriculares Nacionais da Educação Básica (2013). Tais normas tratam das questões aplicadas ao ensino em ambientes formais, sobretudo na escola inserida na esfera pública (municipal, estadual e/ou federal). 
Não obstante, cabe ressaltar que nesta pesquisa não foi possível trazer o olhar reflexivo correlacionado à Base Nacional Comum Curricular (BNCC). Isso porque os debates mobilizados pelo Ministério da Educação, do documento orientador em sua versão preliminar (iniciado em 2015 para consulta pública) sinalizavam para a ausência da Educação de Jovens e Adultos (EJA) no referido documento oficial.

Por conseguinte, em face da ausência da EJA na BNCC, corroborando com análise de Catelli Jr. (2016), havemos de concordar com a necessidade de se construir outro percurso reflexivo sobre questões destinadas à construção de um currículo escolar que busque dialogar com o aspecto da heterogeneidade, com os múltiplos sujeitos e com as diferenças existentes nesse segmento de ensino.

Do ponto de vista do discurso proveniente da legislação, a questão imputada à EJA é observada através da disseminação de discursos sobre os domínios discursivos meramente ideológicos, materializados pelas publicações legais. A citar, por exemplo, a elaboração de propostas curriculares que possibilitem, no contexto escolar, o desenvolvimento de um ensino para 0 enfrentamento do problema existente no cenário educacional, no que diz respeito ao aluno que atinge 15 anos e ainda enfrenta dificuldades para ser alfabetizado.

A Lei 9.394/96 estabelece, na Seção $V$, do Art.37, que "[...] a educação de jovens e adultos será destinada àqueles que não tiveram acesso ou continuidade de estudos no ensino fundamental e médio na idade própria", ou seja, trata-se de uma voz a destacar o direito à educação para uma demanda social escolar que não teve acesso ao estudo na idade própria.

Assim sendo, ressalta-se o aluno incluído em turmas desse segmento de ensino, embora o discurso do marco legal assegure o direito do acesso à escolarização nas diferentes etapas educativas em EJA na Educação Básica. Na verdade, o que predomina na escola é um ensino guiado pelo viés da certificação dos sujeitos sociais envolvidos. A preocupação com a qualidade da prática pedagógica é inexistente. Isto é, a situação real é mais 
centrada no processo de exclusão do aluno, considerando que se torna insuficiente apenas acolhê-lo a partir dos 15 anos no Ensino Fundamental em salas da EJA (MACÁRIO; SENA, 2018).

Diante do exposto, percebe-se que os discursos prescritos pelos documentos oficiais desta etapa educativa, desde a data da sua implantação aos diais atuais, não coadunam com a realidade concreta vivenciada pelo alunado com histórias de insucesso escolar. Por isso, torna-se insuficiente os indicativos das diretrizes curriculares, aplicadas ao contexto dessa modalidade de ensino, que permitam apontar o que é de EJA, não se limitando ao aspecto legal.

É importante ressaltar que, além dessa vertente, se faz necessário pontuar os critérios da elaboração de propostas pedagógicas subsidiadas e estruturadas e de conteúdos escolares capazes de contribuir para o aluno, de fato, assegurando-lhe o direito universal à educação, sem se limitar ao fator do reconhecimento.

Nessa perspectiva, tomemos o seguinte contexto-problema: a situação escolar da sala de aula em que se encontram matriculadas em única turma pessoas com idade entre 15 e 70 anos. É evidente que tais discentes apresentam ritmos diferenciados de aprendizagem e narrativas de histórias de vida configuradas pela exclusão social. Esse cenário ocorre devido à redução de matrículas na instituição de educação básica, por questões não atribuídas ao próprio aluno, contudo por dilemas oriundos de ordem de gestão pública e de políticas públicas a atender os casos de pessoas que não tiveram a chance de estudar na idade certa.

Essa situação ocorre, muitas vezes, por esses discentes não conseguirem conciliar educação e trabalho, o que culmina com o abandono escolar. Razões também atribuídas ao fechamento de turmas e a ausência de investimento na Educação de Jovens e Adultos, o que gera uma redução na oferta de matrículas. Além disso, ressalte-se, muito da evasão dos alunos da EJA dá-se por motivos relacionados ao ensino, motivo pelo qual faz-se imprescindível uma formação docente que possa contribuir para o desenvolvimento do aprendizado desse aluno. 
Diante da mudança da caracterização do perfil dos estudantes em EJA, e ao ter em vista a inclusão do adolescente e do jovem que não sabe ler e escrever, observa-se que a inclusão desses discentes num mesmo espaço com adultos suscita outra preocupação: como garantir a aprendizagem de todos, ao considerar os problemas na formação docente? $E$, simultaneamente, se tais profissionais não concebem o educando da EJA como um ser pensante? Assim, ao considerar as funções sociais atribuídas à escola, Sacristán (2001) endossa que:

O funcionamento dominante da escola, de seu currículo e dos métodos pedagógicos está configurado, geralmente, mais para organizar a desigualdade entre alunos do que para corrigi-la ou conviver com a diversidade de capacidades, de níveis de ritmos de trabalho, de motivações dos sujeitos, etc (SACRISTÁN, 2001, p. 78).

Diante do exposto, cabe ressaltar o aspecto do reconhecimento institucional como um direito que se consolidou na Constituição Federal de 1988, na Lei de Diretrizes e Bases da Educação em 1996 e, notadamente, na busca da melhoria da qualidade do ensino na escola pública. Conforme situa o artigo a seguir:

Art. 37. A educação de jovens e adultos será destinada àqueles que não tiveram acesso ou continuidade de estudos no ensino fundamental e médio na idade própria. $\S 1^{\circ}$ Os sistemas de ensino assegurarão gratuitamente aos jovens e aos adultos, que não puderam efetuar os estudos na idade regular, oportunidades educacionais apropriadas, consideradas as características do alunado, seus interesses, condições de vida e de trabalho, mediante cursos e exames (BRASIL, 1996, p. 27).

Convém sinalizar que tal citação da LDB (9.394/96) chama a atenção para o aspecto do acesso ou da continuidade de estudos no Ensino Fundamental e Médio na idade própria; prevalecendo, portanto, no âmbito escolar, a ideia de EJA voltada para a alfabetização de pessoas adultas. É oportuno destacar que essa modalidade de ensino não se restringe mais à alfabetização, ela também engloba a formação acadêmica de modo geral, incluindo o Ensino Fundamental, séries iniciais e finais, e o Ensino Médio. 
Essa questão é colocada pela Lei de Diretrizes e Bases da Educação Nacional (LDB 9.394/96), no que tange ao Art. 22: "A educação básica tem por finalidade desenvolver o educando, assegurar-Ihe a formação comum indispensável para o exercício da cidadania e fornecer-lhe meios para progredir no trabalho e em estudos posteriores". Nesse contexto, nota-se no cenário escolar, através de discussões reveladas por pesquisas na área da Educação de Jovens e Adultos, um debate a denunciar que os resultados apresentados pela escola atual não vêm garantindo um ensino de qualidade para todos os cidadãos; prova disso é a crescente matrícula de alunos adolescentes na EJA. Desse modo, como garantir o exercício da cidadania e fornecer-lhe meios para progredir no trabalho e em estudos posteriores, se a instituição escolar inviabiliza uma prática pedagógica, com vistas a abarcar esse aluno?

Nessa direção, a crítica recai nas práticas de ensino e, em particular, nos conteúdos abordados nas séries iniciais de Ensino Fundamental. Sendo assim, tal discussão torna-se necessária, entendendo-se que não basta assegurar a oferta de turmas nesta modalidade educativa. De outro modo, faz-se necessário que a gestão de políticas públicas educacionais permita a permanência na escola do educando, além de reunir condições possíveis que facilitem a esse sujeito social cursar todas as etapas da Educação Básica e, finalmente, concluir o Ensino Médio. Convém sinalizar que a formação intelectual do estudante abrange todas as etapas escolares, O que contribui, inclusive, para o acesso dele ao ensino superior.

Ao trazer em pauta uma citação extraída do Art. 22, da LDB 9304/96, ora explicitada, a Proposta Curricular do MEC/Ação Educativa - $1^{\circ}$ Segmento do ensino fundamental - EJA - (1997), no que concerne aos conteúdos apropriados para a escolarização inicial $\left(1^{\circ}\right.$ ao $5^{\circ}$ ano) e à formulação de conteúdos aplicados à sala de aula, apresenta um bloco de conteúdos estruturados por área do conhecimento, a saber: Língua Portuguesa, Matemática e Estudos da Sociedade e da Natureza. Em cada área são definidos seus fundamentos, blocos de conteúdos e objetivos didáticos. 
Nesse documento, observa-se que, na parte destinada ao componente curricular Língua Portuguesa, relativa aos Tópicos de conteúdo e objetivos didáticos - Leitura e escrita de textos (PROPOSTA CURRICULAR/MEC, 1997, p. 84), o foco está voltado para o tópico de conteúdo, que abrange o uso de gêneros discursivos como listas, receitas e instruções, formulários e questionários, anúncios, folhetos e cartazes, dentre outros. Para cada um desses gêneros discursivos citados, a Proposta Curricular apresenta os objetivos didáticos.

Todavia, a preocupação se dá pela constatação de que tal documento não pontua os conteúdos necessários ao discente da EJA para que ele possa produzir determinado gênero discursivo, a exemplo de listas, receitas e instruções. A título de exemplificação, apresenta-se, no Quadrol, a Proposta Curricular do MEC/Ação Educativa - $1^{\circ}$ Segmento do Ensino Fundamental - EJA (1997), acerca da leitura e escrita de texto:

Quadro 1 - Tópicos de conteúdo e objetivo didáticos

\begin{tabular}{|l|l|}
\hline Listas & $\begin{array}{l}\text { Identificar uma lista. } \\
\text { - }\end{array}$ \\
$\begin{array}{l}\text { Produzir listas em forma de coluna ou separando os itens com } \\
\text { vírgulas ou hífens. }\end{array}$ \\
$\begin{array}{l}\text { Escrever diferentes tipos de listas (lista de compras, lista de nomes } \\
\text { de pessoas, nomes de cidades, instrumentos de trabalho, } \\
\text { animais, etc.). }\end{array}$ \\
$\begin{array}{l}\text { Ordenar listas por ordem alfabética. } \\
\text { instruções }\end{array}$ & $\begin{array}{l}\text { Consultar listas classificatórias e ordenativas (dicionários, listas } \\
\text { telefônicas, anúncios classificados, guias de itinerários e ruas), } \\
\text { compreendendo seu critério de organização. } \\
\text { Identificar as partes que compõem uma receita (títulos, lista de } \\
\text { ingrediente, modo e tempo de preparo, ilustrações, fotografias). } \\
\text { Utilizar títulos, ilustrações e outros elementos gráficos como } \\
\text { chaves de leitura para prever conteúdos de receitas e instruções. } \\
\text { Consultar livros, fichas, encartes e suplementos de jornais e } \\
\text { revistas que contenham receitas ou instruções, observando } \\
\text { índice, número da página, organização interna destes materiais. } \\
\text { Escrever receitas, utilizando sua estrutura textual. }\end{array}$ \\
\hline
\end{tabular}




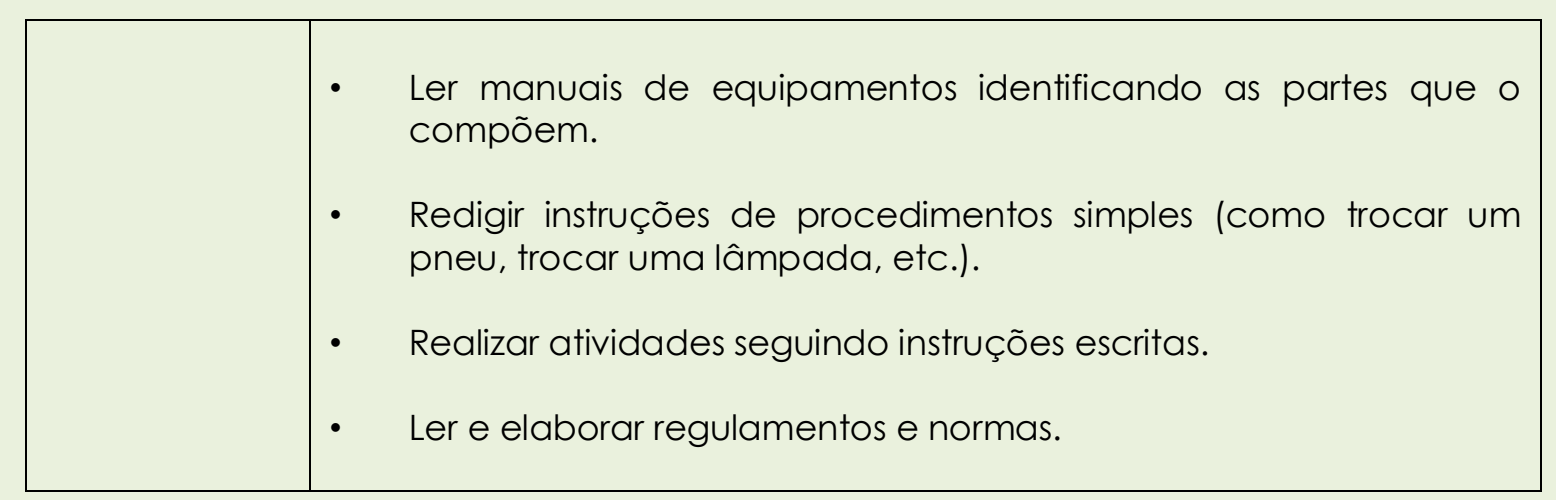

Fonte: Proposta Curricular do MEC/Ação Educativa - $1^{\circ}$ Segmento do ensino fundamental EJA (BRASIL, 1997, p. 84-85).

Todavia, a citação extraída da Proposta Curricular do MEC/Ação Educativa - $1^{\circ}$ Segmento do ensino fundamental - EJA (BRASIL, 1997), e relacionada ao tópico de conteúdo, apresenta nomes de gêneros discursivos e não aponta os conteúdos escolares necessários para a aprendizagem desses textos. É evidente que, no contexto da Educação de Jovens e Adultos, esse discurso não se sustenta frente às demandas sociais desta em relação ao processo da construção dos conhecimentos escolares. Na verdade, o que se torna recorrente na gestão das aulas é a organização das ações escolares, tendo como base os conteúdos curriculares do ensino regular da Educação Básica, na modalidade de Ensino Fundamental ou Médio, como se pode observar na LDB 9.394/96, na Seção $V$, parte específica que trata da Educação de Jovens e Adultos:

Art. 38. Os sistemas de ensino manterão cursos e exames supletivos, que compreenderão a base nacional comum do currículo, habilitando ao prosseguimento de estudos em caráter regular.

$\S 1^{\circ}$ Os exames a que se refere este artigo realizar-se-ão:

I - No nível de conclusão do ensino fundamental, para os maiores de quinze anos; II - No nível de conclusão do ensino médio, para os maiores de dezoito anos.

$\S 2^{\circ}$ Os conhecimentos e habilidades adquiridos pelos educandos por meios informais serão aferidos e reconhecidos mediante exames (BRASIL, 1996).

Diante disso, o ensino em EJA impossibilita a inclusão de qualquer conteúdo nas aulas. As Diretrizes Curriculares Nacionais da Educação Básica (BRASIL, 2013), documento oficial norteador para toda a Educação Básica no país, sinalizam para ações que contribuam para: 
[...] saldar uma dívida social para com o cidadão que não estudou na idade própria. Destina-se, portanto, aos que se situam na faixa etária superior à considerada própria, no nível de conclusão do Ensino Fundamental e do Ensino Médio (BRASIL, 2013, p. 40).

Nesse contexto, o que se percebe é a existência de contradições entre o que estabelece esse texto normativo em relação às observações empíricas do âmbito escolar. Notadamente, a intencionalidade em promover um ensino para sanar tal dívida social, para com uma demanda constituída de jovens e adultos, não se concretiza. Esse mesmo regulamento preceitua que os conteúdos da modalidade de ensino citada anteriormente compreendem os mesmos conteúdos escolares pertencentes à Matriz curricular da Educação Básica, então considerada regular, como assinalado a seguir:

Os cursos de EJA devem pautar-se pela flexibilidade, tanto de currículo quanto de tempo e espaço, para que seja:

- Rompida a simetria com o ensino regular para crianças e adolescentes, de modo a permitir percursos individualizados e conteúdos significativos para os jovens e adultos;

- Provido suporte e atenção individual às diferentes necessidades dos estudantes no processo de aprendizagem, mediante atividades diversificadas;

- Valorizada a realização de atividades e vivências socializadoras, culturais, recreativas e esportivas, geradoras de enriquecimento do percurso formativo dos estudantes;

- Desenvolvida a agregação de competências para o trabalho;

- Promovida a motivação e orientação permanente dos estudantes, visando à maior participação nas aulas e seu melhor aproveitamento e desempenho;

- Realizada sistematicamente a formação continuada destinada especificamente aos educadores de jovens e adultos (BRASIL, 2013, p. 41).

Diante do exposto, observa-se um quadro de mera repetição por parte daqueles que se debruçam a estudar a EJA e a explicitar o que os textos legais asseguram para a demanda social e que, portanto, tratam de uma proposta de ensino voltado a garantir o direito à educação para todos aqueles que tiveram acesso à escola na faixa etária adequada.

Nesse sentido, reporta-se à contribuição do documento oficial, intitulado Artigo 26, da Declaração Universal dos Direitos Humanos de 1948 , 
que estabelece o direito de todos ao "desenvolvimento pleno da personalidade humana" e como uma necessidade para fortalecer o "respeito aos direitos e liberdades fundamentais". Nesse embate, em torno da defesa da EJA, subjacente à ideia de educação como direito, é relevante reiterar que a concepção defendida na $V$ Conferência Internacional de Hamburgo (1997) compreende a formação de jovens e adultos como um processo de educação ao longo da vida, na busca da autonomia e do senso de responsabilidade dos indivíduos e das comunidades.

Doravante, nesse processo, fortalece-se a capacidade de lidar com as transformações que ocorrem na economia, no trabalho, na cultura e nas relações sociais, atentando para as discrepâncias geracionais, de gênero, etnia, entre jovens e adultos inseridos nos centros urbanos e rurais.

Apesar disso, o que se observa, por um lado, é o fato da insistência de publicações curriculares que explicitam como desenvolver os conteúdos em contextos da EJA, de modo a levar, para as demandas e necessidades dos sujeitos sociais, os conteúdos denominados científicos. Acrescidos a esse fator, constata-se, nos planejamentos escolares, por outro lado, a ausência de cursos de licenciatura de formação inicial docente para lidar com o perfil escolar da EJA. O que se percebe é a atuação de professores oriundos do ensino regular, especificamente, aqueles que lidam com crianças. Como sinaliza Paiva (2006, p. 521):

[...] professores quase sempre formados para lidar com crianças acabam "caindo", no âmbito dos sistemas, em classes de jovens e adultos com pouco ou nenhum apoio ao que devem realizar. Também educadores populares, plenos de verdades sob o prestígio da educação popular, descrevem concepções pautadas em um tempo, em uma realidade social cujo movimento se altera, necessariamente, por ser histórico, sem que as enunciações o acompanhassem.

Com efeito, a divulgação desse direito não é suficiente para a garantia do acesso à Educação Básica, mas, especificamente, a caminhos possíveis para se criarem condições cujas estratégias metodológicas 
favoreçam a permanência dos jovens, adultos e idosos nos diferentes contextos escolares e, independentemente da modalidade educativa, para se conseguir a conclusão da escolarização com o direito a aprender.

Na verdade, é comum nas práticas pedagógicas da EJA o conteúdo ser trabalhado na perspectiva do acolhimento e da conscientização social. Nessa linha de pensamento, o que se percebe na cultura escolar é o entendimento de que, devido à especificidade desse participante, a escola básica passa a desconsiderar os conteúdos indicados para cada ano ou série nesse segmento de ensino. As disciplinas passaram a representar um amontoado de conhecimentos prontos e acabados, que, na verdade, só servem para serem trabalhados nos espaços formais; dotando-as de uma única finalidade, a de reprovar o aluno. Isso ocorre, muitas vezes, pela interpretação equivocada estabelecida pela cultura escolar, extinguindo-se os conteúdos por desacreditar no potencial intelectual do discente, o que carrega o estigma de fraco, como fruto do fracasso escolar.

Nos estabelecimentos oficiais de educação, tornam-se comuns os questionamentos de professores sobre as dificuldades do ensino para contribuir com a formação dos partícipes enquanto sujeitos epistêmicos. Como advoga Nóvoa (2009), em relação ao olhar da escola frente a essa questão:

\begin{abstract}
A escola no centro da coletividade remete para uma instituição fortemente empenhada em causas sociais, assumindo um papel de 'reparadora' da sociedade; remete para uma escola de acolhimento dos alunos e, até, de apoio comunitário às famílias e aos grupos mais desfavorecidos; remete para uma escola transbordante, uma escola utópica que procura compensar as 'deficiências da sociedade', chamando a si todas as missões possíveis e imagináveis (NÓVOA, 2009, p. 60).
\end{abstract}

Diante do exposto, podemos formular a seguinte proposição: existe, de fato, um conteúdo a ser direcionado para as práticas pedagógicas específicas em EJA ou, na verdade, a EJA se insere no campo das discussões ideológicas? Como fica a função social da escola? 
Outro importante documento se refere às Diretrizes Curriculares Nacionais (BRASIL, 2000), cuja abordagem definiu como objetivos para a EJA restaurar o direito à educação, negada aos jovens e adultos, assim como oferecer a eles igualdade de oportunidade para a entrada e permanência no mercado de trabalho e qualificação para uma educação permanente (SOARES, 2002).

Nessa dimensão, há um direcionamento de que o ensino deve ser pensado como um currículo capaz de criar situações de ensinoaprendizagem adequadas às necessidades educacionais desse público, englobando as três funções citadas no Parecer 11/00 da CEB: a função reparadora, caracterizada pela entrada no circuito dos direitos civis e pela restauração de um direito negado, o direito a uma escola de qualidade e o conhecimento de igualdade de todo e qualquer ser humano; a função equalizadora, centrada em um atendimento pleno e legal a trabalhadores e a tantos outros segmentos da sociedade, possibilitando-lhes a reentrada no sistema educacional, e; a função permanente, voltada para uma educação de jovens e adultos, que deve dar condições ao aluno de atualizar conhecimentos por toda a sua vida.

Nesse sentido, ao olhar para a prática educativa na educação básica, o que se vê é a utilização da nomenclatura "EJA", que envolve um quadro específico de professores, com uma formação docente inicial voltada para um público do ensino regular e que, ao organizar a sua atividade docente, tende a uma atividade pedagógica centrada na figura do alunado numa perspectiva da educação regular. A crítica apontada é que a escola passa a encaminhar o processo educativo de "qualquer jeito".

$\mathrm{Na}$ verdade, o que prevalece no âmbito dessas discussões é o interesse em um ensino, como já foi citado, mais centrado na vertente do discurso da certificação dos alunos, preocupado com a inserção do discente no mercado de trabalho. Esse estudante se alfabetiza de qualquer jeito e sente-se incapaz de pensar, inclusive, em cursar um curso superior. Ou seja, trata-se de um educando que vem de práticas escolares com o uso de métodos de ensino pautados na mera alfabetização, configuradas de 
práticas de leitura e escrita como mera decodificação, estudos de sílabas e palavras descontextualizadas com relação à formação do leitor.

Contudo, diante do tema tratado anteriormente, no intuito de refletir os discursos que são disseminados na cultura escolar no contexto da EJA, propõe-se discutir, na próxima seção, o olhar desses discursos oficiais no interior da escola, no sentido de observar o processo educacional de inclusão do aluno do Ensino Fundamental desta etapa de ensino.

\section{OS SUJEITOS DA EJA: pessoas jovens, adultas e idosas em situação de diversidade}

A caracterização dos sujeitos da EJA passa, desde o início da segunda década deste século, por mudanças perceptíveis nos contextos escolares. $\mathrm{Se}$, antes, a sala de aula era composta basicamente por pessoas adultas e o interesse de estudar estava associado à alfabetização, percebe-se que, hoje, tal realidade tende a ser modificada. Essa transformação tem ocorrido, notadamente, devido à presença dos adolescentes e dos jovens com passagens no Ensino Fundamental regular, que exigem práticas pedagógicas mais dinâmicas e comprometidas com perspectivas de inserção social em que a escolarização tem lugar central.

Na verdade, essa situação descrita anteriormente impõe ao professor maiores desafios quanto ao ensino de leitura no contexto escolar. Pois, observa-se que o docente, com atuação nas séries iniciais do Ensino Fundamental (EJA), além de lidar com pessoas de diferentes idades, passa a resolver os problemas dos alunos mais jovens que vêm da escola diurna, quase sempre porque esta foi incapaz de reconhecê-los como sujeitos aprendentes.

Tal mudança verificada no ensino da EJA reflete o aspecto da heterogeneidade no perfil desses sujeitos, inseridos nas turmas das séries iniciais, e chama a atenção para a realidade na qual o professor terá que lidar com alunos em uma única turma. Destaca-se neste contexto de diversidade o campo da formação para a leitura em sentido amplo, quase sempre associado às histórias de fracasso ou evasão na educação regular. 
Diante do perfil discente já citado, é oportuno enfatizar que não se trata apenas de um alunado que jamais passou pela escola. Contudo, de pessoas que, embora tenham frequentado esse espaço, permaneceram sem o domínio da leitura. Os estudantes jovens têm sido vistos como indisciplinados, o que gera dificuldades relativas ao agir docente. Uma vez que a própria formação docente enfrenta dificuldades no reconhecimento da realidade revelada dos "[...] modos de ser jovem que apresentam especificidades, o que não significa, porém, que haja um único modo de ser jovem nas camadas populares. [...] torna-se necessário articular a noção de juventude à de sujeito social" (DAYRELL, 2013, p. 42).

O discente, inserido na Educação Básica, em especial na EJA, já participa dos usos sociais da leitura/escrita nas situações habituais e informais, antes mesmo de sua inserção na instituição de ensino. Dada essa realidade, a escola deve atentar para o uso social da leitura no cotidiano do aluno e, ao contemplar o ensino em processo de alfabetização/letramento, em turmas de alfabetização na EJA, entende-se ser mais produtivo destacar uma prática de sala de aula na qual o currículo venha a atender as especificidades dessa demanda escolar, levando em consideração os aspectos motivacionais que derivaram na busca à escola.

Carrano (2008, p. 206) enfatiza que se torna necessário que os professores reflitam sobre uma possível reorganização curricular "capaz de desenvolver a comunicação com os sujeitos concretos da escola, sem que, com isso, se abdique da busca de inventariar permanentemente a unidade mínima de saberes em comum, que as escolas devem socializar". Nesse entendimento, Dayrell (2007) salienta que:

[...] A escola tem de se perguntar se ainda é válida uma proposta educativa de massas, homogeneizante, com tempos e espaços rígidos, numa lógica disciplinadora, em que a formação moral predomina sobre a formação ética, em um contexto dinâmico, marcado pela flexibilidade e fluidez, de individualização crescente e de identidades plurais. Parece-nos que os jovens alunos, nas formas em que vivem a experiência escolar, estão dizendo que não querem tanto ser tratados como iguais, mas, sim, reconhecidos nas suas especificidades, o que implica serem reconhecidos como jovens, na sua diversidade, um momento privilegiado de construção de 
identidades, de projetos de vida, de experimentação e aprendizagem da autonomia (DAYRELL, 2007, p. 1125).

A presença de vários grupos etários apresenta, portanto, protagonistas de histórias reais, constituídos de adolescentes, mulheres, homens, jovens, adultos, idosos, pessoas com necessidades especiais, entre outros, que revelam trajetórias de experiências de negação ao direito à educação formal, de desigualdade social e de exclusão social.

No que concerne às múltiplas tensões em EJA, particularmente no ato da organização de atividades escolares, focadas nas práticas de leitura, é possível identificar a questão das faixas etárias distintas e da diversidade geracional. Nesse contexto, encontram-se sujeitos sociais que, apesar de pertencerem a um mesmo grupo etário, apresentam-se como sendo relacional e socialmente diferentes. É sabido que a heterogeneidade, em relação ao intervalo de idade, revela uma presença considerável de educandos adolescentes e jovens que, uma vez inseridos no quadro de distorção série/idade, passam a frequentar a sala de aula nessa modalidade educativa, além de casos de deslocamentos regionais de sujeitos sociais agrupados em um único espaço escolar, que necessitam da aprendizagem da leitura.

Candau (2008), ao acentuar a relevância da questão cultural voltada ao campo da educação, argumenta que a perspectiva intercultural busca promover uma educação para o reconhecimento do "outro", para o diálogo entre os diferentes grupos sociais e culturais, e se encontra orientada para a construção de uma sociedade democrática, plural, humana, que articule políticas de igualdade com políticas de identidade. Por conseguinte, enfatiza:

[...] Algumas doutrinas pedagógicas concorreram para acentuar atitudes equivocadas por parte de educadores na escola. Teorias que afirmam a carência cultural, ainda que rejeitadas atualmente, deixaram marcas na prática pedagógica, justificando o fracasso escolar única e exclusivamente pela 'falta de condições' dos alunos. Esse tipo de estigma 'contagiou' professores e escolas. Por ocasião do processo de ampliação das oportunidades educacionais, sobretudo a partir da década de 70, tornou-se comum certa 
argumentação que vinculava, indevidamente, a queda da qualidade do ensino ao acesso das camadas populares a uma escola que fora, até então, explicitamente seletiva (BRASIL, 1997, p. 126).

Nesse sentido, em comum acordo com tais argumentos, é importante que se destaque que o trabalho educativo no contexto escolar, especificamente na modalidade de ensino da EJA, é momento crucial para levar em consideração o diálogo entre as culturas, considerando que, no espaço escolar, há diferentes estudantes, com distintas expectativas e histórias de vida.

Todavia, para buscar as estratégias de leitura, de modo a agregar os diferentes alunos, é necessário perpassar pelo estudo de teorias, modelos mentais e processo de letramento. Conforme sinalizado por SENNA (2007, p.68):

[...] implica, portanto, pluralizar-se a concepção de sujeito epistemológico, com base em uma concepção que o tome a partir de uma vinculação, entre seu próprio potencial cognitivo e os arranjos possíveis decorrentes das inúmeras possibilidades interacionais que o tomam no corpo no interior dos conceitos instituídos em sua história social.

A partir disso, torna-se possível chegar à compreensão de que a prática de leitura no contexto escolar, da modalidade educativa citada anteriormente, mobiliza o estudo das concepções de leitura atreladas às exigências da sociedade contemporânea, em que se faz necessário ressignificar a práxis educativa da Língua Materna, sob o foco da leitura, em diferentes contextos socioculturais.

Na realidade, é perceptível em EJA uma cultura escolar difundida através dos diferentes discursos que ecoam no âmbito escolar a disseminar a concepção de um modelo de aula numa perspectiva ideológica, como "apropriada" para essa modalidade, a buscar ações voltadas para a inclusão social do aluno. Ocorre que tal modelo de aula não apresenta inovações em relação às práticas escolares, compreendendo o estudante em situação de insucesso escolar. 
Isso ocorre pelo fato de a escola trilhar pelos encaminhamentos curriculares centrados em propostas pedagógicas que se dizem para a demanda social. Percursos esses correlacionados à EJA. Além de prevalecer uma prática docente pautada nos princípios norteadores do ensino regular, resultando em quadro de reprovações e abandono da sala de aula por parte do estudante. Quanto ao problema de formação docente para atuação na EJA, os estudos de Freitas e Cavalcante (2014) advertem:

\begin{abstract}
As políticas públicas de leitura têm atuado quase sempre fragmentadas, não incentivando uma formação continuada específica para os/as educadores/as e para aqueles/as que são responsáveis pelas salas de leitura, que em sua maioria são professores/as readaptados, em desvio de função da regência de sala de aula. Focalizam apenas a necessidade das escolas e dos/as professores/as incentivarem o gosto pelo ato de ler, diante de um acervo predominantemente de livros didáticos. Outra lacuna existente nas escolas, quando da realização de ações para se despertar o prazer pela leitura, é que não se tem explícito a definição sobre que tipo de leitor se pretende formar. Não se reflete sobre os aspectos referentes aos eventos e práticas de letramento que estão ocorrendo nas salas de aula, da mesma forma, não se enfatiza a importância de os professores conhecerem as teorias sobre processamento de leitura, conhecimento esse necessário, mas que na sua maioria, não tiveram na sua formação inicial (FREITAS; CAVALCANTE, 2014, p. 94).
\end{abstract}

Diante do exposto, observa-se um hiato existente entre o proclamado pelas políticas públicas de incentivo à leitura e o desafio da formação de professores frente ao que preconiza o Parecer do MEC: "A rigor, as unidades educacionais da EJA devem construir, em suas atividades, sua identidade como expressão de uma cultura própria que considere as necessidades de seus alunos e seja incentivadora das potencialidades dos que as procuram" (BRASIL, 2000, p. 35).

Em seus estudos sobre os saberes necessários para o docente com jovens, adultos e idosos, Romão (2014), ao considerar suas vivências pessoais e como pesquisador freiriano, assevera que Paulo Freire pontuava sempre que "não deveríamos constituir uma seita, uma confraria de discípulos, nem repetir suas ideias, mas reinventá-las em cada contexto" (ROMÃO, 2014, p. 46). Nesse sentido, há um entendimento de que se pode avançar nos 
estudos epistemológicos quanto aos modos de produção de conhecimento na escola voltada para jovens e adultos.

Doravante, de acordo com Charlot (2013, p. 149), o que se torna relevante "é que o ensino tenha sentido, não é o que esteja ligado ao mundo familiar do aluno; esta opção representa apenas uma solução possível em certos casos e pode ser perigosa ou impossível em outros". Por consequência,

\begin{abstract}
Para relacionar-se ao mundo como objetos de pensamento são fundamentais os processos de distanciação-objetivação e de sistematização. A distanciação possibilita ao aluno sair do mundo subjetivo das emoções, dos sentimentos, da experiência vivenciada e pôr o mundo como objeto a ser pensado. Distanciação e objetivação são indissociáveis e ocorrem em um só processo: o Eu constitui-se em um Eu epistêmico, distinto do Eu empírico, no processo pelo qual ele coloca o mundo como objeto de pensamento. Este processo de distanciação - objetivação - só é possível graças à linguagem; somente pela linguagem podem existir objetos de pensamento e um sujeito racional para pensá-los (Vygotsky, 1987). Se na escola impera a linguagem, é porque esta possibilita construir objetos de pensamentos diferentes dos objetos de vivência, o que é a especificidade da escola (CHARLOT, 2013, p. 149).
\end{abstract}

Como consequência, o que se vê no cenário da Educação de Jovens e Adultos, em relação ao ensino que se presta a cumprir com a função da escola, como foi explicitado em Charlot (2013), é um cenário educacional de contradição. Nessa direção, este enfatiza serem de fundamental relevância os saberes necessários para compreender os modos de pensamento e de como o discente aprende os conteúdos. Além disso, é necessário, principalmente entre os aspectos a pontuar nesse momento da formulação curricular, procurar apreender as concepções epistemológicas que contribuem para o desenvolvimento da aprendizagem escolar em relação aos conteúdos considerados necessários para o desenvolvimento da formação do sujeito epistêmico.

Sendo assim, além dos aspectos ora citados, há muita ênfase no ensino da EJA, uma cultura enraizada nos aspectos derivados de questões sociais, fruto da desigualdade social e, consequentemente, da exclusão social. Disso, repercute-se a atenção a uma pedagogia centrada em olhar 
esse ser humano como "coitadinho", vitimizado, com uma história de vida que preocupa parte de professores e especialistas na escola, fazendo-os enfatizar a questão da exclusão social, em vez de partir para trabalhar os conteúdos curriculares com os sujeitos da EJA.

Em seus estudos, ao discorrer sobre políticas educacionais, Libâneo (2016) reitera que as políticas oficiais, voltadas para a escola no contexto brasileiro, pautam-se por duas orientações curriculares complementares, que se encontram correlacionadas à orientação das políticas de contenção da pobreza, atendendo às estratégias de manter a competitividade no contexto da globalização e da diversificação dos mercados. Esse autor enfatiza que, na maioria dos estados brasileiros, predominam a existência de um currículo instrumental ou de resultados imediatos, que se caracteriza como um conjunto de conteúdos mínimos necessários ao trabalho e emprego, associado ao currículo de convívio e acolhimento social, com forte apelo à inclusão social e ao atendimento da diversidade social, objetivando formar para um tipo de cidadania baseado na solidariedade e na contenção de conflitos sociais.

\section{ALGUMAS CONSIDERAÇÕES}

A partir das discussões suscitadas neste trabalho, no que se refere à Educação de Jovens e Adultos (EJA), percebe-se a existência de uma lacuna entre os desdobramentos dos discursos que emergem no contexto escolar, em relação a pensar práticas pedagógicas para as demandas sociais dessa modalidade, focadas em um ensino que se presta à inclusão social do sujeito, levando em consideração a função social da escola.

O debate suscitado pelos discursos acadêmicos evidencia a necessidade de se discutir acerca da concretização de práticas pedagógicas, sob o viés da educação inclusiva, capaz de assegurar ao jovem, adulto e idoso um espaço na escola destinado à produção de conhecimento. Isso é posto, neste estudo, tendo em vista a existência, na cultura escolar, em relação ao indivíduo que frequenta o ensino na modalidade da Educação de Jovens e Adultos, da repercussão negativa 
para com esse discente que, uma vez pertencente à categoria aluno da EJA, não é reconhecido como um sujeito social capaz de aprender os conteúdos escolares.

Convém ressaltar ainda a ausência de políticas públicas e de programas de governo, no campo das séries iniciais, que desconsiderem práticas pedagógicas à luz da teoria tradicional, que incide em uma pedagogia mecanicista a reprovar os estudantes. Há de se considerarem, neste estudo, os apontamentos teóricos e metodológicos que mais se aproximam do jovem, adulto e idoso na sala da aula da modalidade educativa já citada, em situação de diversidade e com distintos níveis de aprendizagem. Ao trazer em pauta contribuições de pesquisas que tratam na cultura escolar da EJA, apresentamos uma contribuição que mais sintetiza o pensamento defendido neste texto, apoiados a ótica de Charlot (2013). Pois, se o aluno fracassa na escola, não significa dizer que ele não tem uma atividade intelectual apropriada ao empoderamento dos saberes e da construção de competências cognitivas.

Por tudo isso, depreende-se que o conhecimento da demanda escolar em EJA possibilitará ao educador a sistematização de ações escolares a encontrar o aluno tido como diferente em relação ao modelo conceitual universal, de um sujeito cartesiano, nos moldes da cultura científica. É oportuno destacar que o ensino, nas turmas dos anos iniciais de Ensino Fundamental, não pode permanecer prefixado a determinados tipos de receitas prontas e acabadas, que se traduzem como sendo para serem aplicadas ao contexto da Educação de Jovens e Adultos. Mas que, particularmente, se aproxime dos sujeitos sociais, partindo da perspectiva que o conteúdo da formação docente deve propiciar espaços de diálogo com os diferentes interlocutores existentes na sala de aula.

Falar no reconhecimento da heterogeneidade presente no cotidiano escolar salienta a necessidade de produção de um conhecimento que embase o professor a conviver com o aspecto da diferença entre os alunos, do ponto de vista do movimento atrelado à redefinição das práticas pedagógicas a incluir os alunos com níveis diferenciados de aprendizagem. 
Tal situação exige do professor pensar, no ato do seu planejamento, o desenvolvimento de práticas pedagógicas, o que perpassa, inclusive, pela formação docente em relação à mudança das práticas escolares, ao ensino da Língua Materna, à possibilidade de dialogar com os diferentes sujeitos sociais e buscar, através de práticas de alfabetização, numa perspectiva de letramento, contribuir para a participação cidadã e a inserção social dos sujeitos que acorrem à escola da EJA.

\section{REFERÊNCIAS}

BRASIL. Lei № 9.394 de 20 de dezembro de 1996. Brasília, 1996.

BRASIL. Proposta Curricular do MEC/Ação Educativa: $1^{\circ}$ Segmento do Ensino Fundamental - EJA. Brasília, 1997.

BRASIL. Diretrizes Curriculares Nacionais da Educação Básica. Brasília, 2013.

CANDAU. V. M. Direitos humanos, educação e interculturalidade: as tensões entre igualdade e diferença. Revista Brasileira de Educação, v. 13, n. 37 jan./abr. 2008.

CARRANO, P. C. R. Educação de Jovens e Adultos e Juventude: o desafio de compreender os sentidos da presença dos jovens na escola da "segunda chance". Revista de Educação de Jovens e Adultos, 2008.

CATELLI JR, R., et. al. Proposições de organização curricular na educação de jovens e adultos. Cadernos cenpec, São Paulo, v. 3, n. 2, p. 162-186, jun. 2013.

CATELLI JR, R.; Roberto Catelli Jr. fala sobre Educação de Jovens e Adultos. Entrevista concedida a Nova Escola. 4 ago. 2016. Disponível em: <https://novaescola.org.br/conteudo/357/robertocatelli-jr-fala-educacaojovens-adultos>. Acesso em: 15 fev 2020.

CHARLOT, B. Da relação com o saber às práticas educativas [livro eletrônico]. 1. ed. São Paulo: Cortez, 2013.

DAYRELL, J. A escola "faz" as juventudes? Reflexões em torno da socialização juvenil. Educação e Sociedade, Campinas, v. 28, n. 100, Especial, p. 1.1051.128 , out. 2007.

DAYRELL, J. A Juventude e Suas Escolhas: as relações entre projeto de vida e escola, In: VIEIRA, M. M. et al. (Orgs.). Habitar a Escola e as Suas Margens: geografias plurais em confronto. Porto Alegre, RS, 2013. Cap. 2, p. 65-72. 
FREITAS, M. Q.; CAVALCANTE, V. C. Leitura na Educação de Jovens e Adultos e a formação de leitores. Perspectiva, Florianópolis, v. 32, n. 1, 93-109, jan./abr. 2014.

LIBÂAEO, J. C. Políticas educacionais no Brasil: desfiguramento da escola e do conhecimento escolar. Cadernos de Pesquisa, v. 46, n. 159, p. 38-63, 2016.

MACÁRIO, R. O. Práticas de letramento na educação de jovens e adultos: a revista como possibilidade de formação do leitor crítico. Dissertação de Mestrado. Universidade Estadual da Paraíba, 2014.

MACÁRIO, R. O.; RODRIGUES, L. P. A leitura na educação de jovens e adultos. In: ARANHA, S. D. G.; SOUSA, F. M. (Org.). Práticas de ensino e tecnologias digitais. Campina Grande: EDUEPB, 2018. p. 428-467.

MACÁRIO, R. O.; SENNA, L. A. G. Reflexões sobre a formação de leitores em EJA: saberes necessários para a prática docente. Revista linguagens,

Educação e Sociedade. v. 38. p. 51-71, 2018.

NÓVOA, A. Professores: Imagens do futuro presente. Lisboa: Educa, 2009.

Pacheco (2007; 2016a; 2016b) e Libâneo (2016).

PAIVA, J. Tramando concepções e sentidos para redizer o direito à educação de jovens e adultos. Revista Brasileira de Educação, n. 33, p. 519539, 2006.

PAIVA, J.; HADDAD, S.; SOARES, J. Pesquisa em educação de jovens e adultos: memórias e ações na constituição do direito à educação para todos. Revista Brasileira De Educação, Rio de Janeiro, RJ. v. 24 de jan. /2019, p.1-25.

ROMÃO, J. E. Paulo Freire e a Educação de Jovens e Adultos. EJA em debate, Florianópolis, ano 3, n. 4, jul. 2014.

SACRISTÁN, J. G. A educação obrigatória: seu sentido educativo e social. Porto Alegre: Artmed, 2001.

SOARES, L. (Org.). Diretrizes Curriculares Nacionais: Educação de jovens e adultos. Rio de Janeiro: DP\&A, 2002.

UNESCO. Declaração de Hamburgo sobre a Educação de Adultos e Plano de Ação para o Futuro. V Conferência Internacional sobre Educação de Adultos. Hamburgo, Alemanha, 14-18 jul. 1997. 
Recebido em: 13 de maio de 2020 Aprovado em: 15 de setembro de 2020

Publicado em: 18 de novembro de 2020

(c) (1) (5) 